\title{
Aliphatic hydrocarbon pollution and macrobenthic assemblages in Ceuta harbour: a multivariate approach
}

\author{
J. M. Guerra-García ${ }^{1, *}$, F. J. González-Vila ${ }^{2}$, J. C. García-Gómez ${ }^{1}$ \\ ${ }^{1}$ Laboratorio de Biología Marina, Dpto. Fisiología y Zoología, Facultad de Biología, Avda. Reina Mercedes 6, \\ 41012 Sevilla, Spain \\ ${ }^{2}$ Instituto de Recursos Naturales y Agrobiología de Sevilla, Consejo Superior de Investigaciones Científicas, Apdo. 1052, \\ 41080 Sevilla, Spain
}

\begin{abstract}
The aliphatic hydrocarbon composition of sediments from Ceuta harbour, North Africa, was studied to determine the sources, levels and effects of these hydrocarbons on macrofauna composition by considering indices and concentration ratios in multivariate analyses. A total of 21 stations (15 inside and 6 outside the harbour) were sampled using a van Veen grab. High hydrocarbon concentrations (496 to $6972 \mathrm{ppm}$ ), the dominance of the UCM (unresolved complex mixture) in relation to the resolved alkanes, and values close to the unity $(\approx 1)$ of the CPI (carbon preference index) and pristane:phytane ratio indicated anthropogenic origins of the hydrocarbons. Ceuta harbour is characterised by intense traffic, and frequent loading and dumping related to shipping operations. Furthermore, 2 urban effluent outfalls of Ceuta city flow into the harbour. The relationship between macrofauna and the above-measured parameters was evident in canonical correspondence analysis (CCA). Variation in species composition at different sample stations was related to the ratios of maltenes to other hydrocarbons, pristane:phytane and, especially, maltenes:asphaltenes, which turned out to be the main factor discriminating between internal and external stations according to species distribution. The crustaceans Corophium runcicorne and C. sextonae, the mollusc Parvicardium exiguum and the polychaete Pseudomalacoceros tridentata were only found at internal stations, while the polychaetes Jasmineira elegans and Scoloplos armiger were present only at external stations. The abundance of the crustaceans Apseudes latreilli, Leptochelia dubia and Pariambus typicus, and the polychaetes Capitella capitata, Nereis falsa and Potamilla reniformis, differed significantly between the internal and external stations. Although the asphaltene fraction is potentially hazardous to sediment macrofauna, due to its high molecular weight and its slow degradation, the relationship between the distribution of marine organisms and the presence of asphaltenes has never been explored in previous studies.
\end{abstract}

KEY WORDS: Aliphatic hydrocarbon pollution $\cdot$ Maltenes:asphaltenes $\cdot$ Macrofauna $\cdot$ Multivariate analysis $\cdot$ Ceuta harbour

Resale or republication not permitted without written consent of the publisher

\section{INTRODUCTION}

There are too few studies assessing the relationship between macrobenthic assemblages and multivariate analytical chemical data in order to describe hydrocarbon pollution. Hydrocarbons are ubiquitous organic contaminants in the marine environment. Although many hydrocarbons are synthesised by organisms and normally occur in the biosphere, a large proportion is derived from sources related to human activities, constituting one of the largest and most widespread classes of organic pollutants (Bouloubassi et al. 2001). The main sources of anthropogenic hydrocarbons in the marine environment are industrial effluents, 
sewage disposal, riverine discharges, loading and dumping associated with shipping operations, offshore oil production and accidental oil spills (NoboruNishigima et al. 2001).

The long-term effects of oil pollution are still not completely understood. It is generally recognised that oil resides in the water column for a relatively short time, and that the area of greatest concern is the sediments, where most of the released oil is deposited, and often remains for many years (Vandermeulen \& Gordon 1976).

Although many studies on hydrocarbon data in sediments have been published (Bouloubassi et al. 1997, Choiseul et al. 1998, Al-Omran \& Rao 1999, Dachs et al. 1999, Pereira et al. 1999, Gogou et al. 2000, Louati et al. 2001, Wu et al. 2001, Parga-Lozano et al. 2002, Readman et al. 2002, Sharma et al. 2002), no biological data of macrofauna abundances are reported. Furthermore, a multivariate approach, including the relationship between soft-bottom macrofaunal assemblages and the chemical parameters of hydrocarbons, is lacking. When a multivariate approach is used to analyse the macrobenthic community structure in relation to environmental data (Dauer et al. 1993, Estacio et al. 1997, Saíz-Salinas 1997, Rakocinski et al. 2000, Preston 2002), only total values of hydrocarbons are incorporated into a more general environmental matrix (together with data of heavy metals, PCBs, DDTs, etc.), and no data of hydrocarbon distribution at the mole-

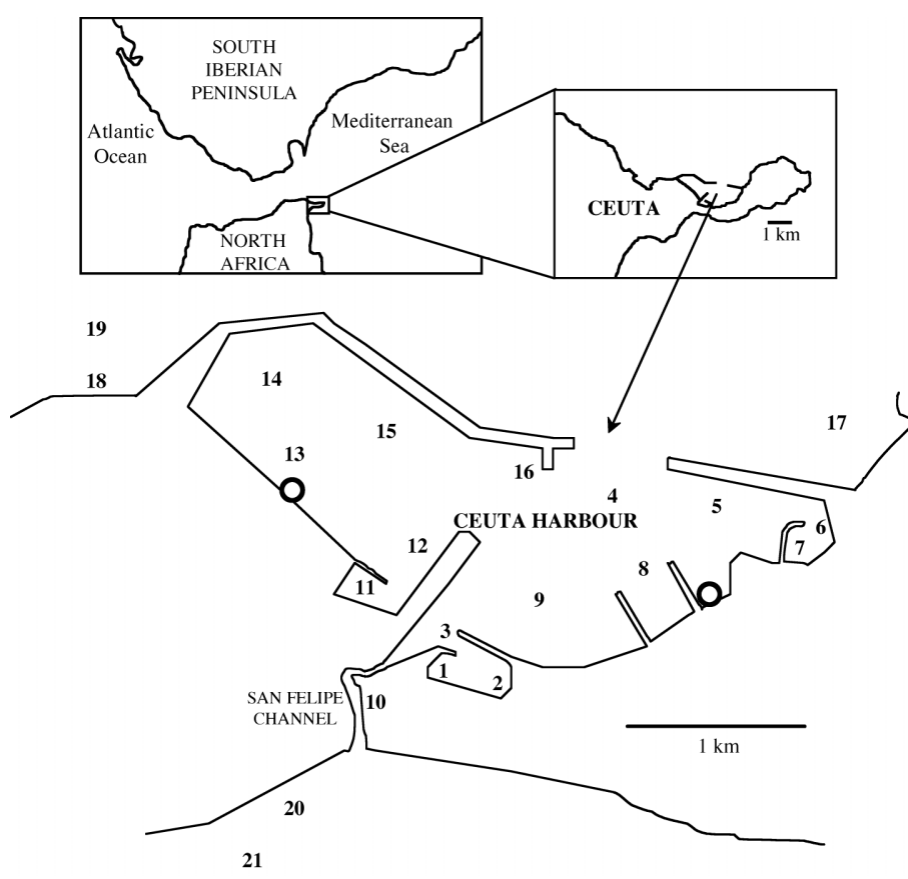

Fig. 1. Ceuta harbour, North Africa, and sampling stations (Stns 1 to 21). Circles: inputs of sewage effluent cular level, or ratios and indexes, are considered for multivariate analysis. These hydrocarbon parameters are included exclusively in chemical studies in which biological information is not reported (Bouloubassi et al. 2001, Noboru-Nishigama et al. 2001, Wu et al. 2001).

Apart from occasional studies on the relationship between soft-bottom macrofauna and polycyclic aromatic hydrocarbons (PAH) (Oug et al. 1998), there is a complete lack of studies exploring the relationship between macrobenthic assemblages and aliphatic hydrocarbon parameters. To fill this gap, the results from a study conducted on surface sediments collected in Ceuta harbour are presented. We focus specifically on aliphatic compounds to determine their source, levels and biological implications in macrobenthic community composition by considering indices and concentration ratios utilising multivariate analyses.

\section{MATERIALS AND METHODS}

Study area. The study was conducted in Ceuta harbour, located along the North African coast (at $35^{\circ} 53^{\prime} \mathrm{N}, 5^{\circ} 18^{\prime} \mathrm{W}$ ) (Fig. 1). It is one of the most important harbours in the Strait of Gibraltar, providing a gateway from Europe to Africa. Ceuta harbour is characterised by intense shipping traffic, and frequent loading and dumping is involved in shipping operations. Two urban effluent outfalls of Ceuta city flow into the harbour, but there are no river discharges. Unlike other harbours of southern Spain, such as Algeciras Port (Estacio et al. 1997), industrial activity adjacent to Ceuta harbour and city is very scarce. Therefore, the contamination in Ceuta harbour is mainly derived from shipping activities and sewage disposal points. During the 1960s and 1970s, control of loading and dumping in shipping operations was not effective, and several accidental oil spills occurred inside Ceuta harbour.

The depth in our study area ranges between 3 and $16 \mathrm{~m}$, and most of the harbour bottom and external nearby areas are formed by soft sediments of different granulometry. The harbour is located between 2 bays connected by a channel (Fig. 1). This channel increases the water movement and renewal along some areas of the harbour and increases the heterogeneity in sediment structure.

Sample collection. Sampling was carried out in June 1999. A total of 21 stations (15 inside and 6 outside the harbour) were chosen (Fig. 1). The exact location was determined by the absence of rocky outcrops, with depth varying between 3 and $16 \mathrm{~m}$. Stn 10, located in San Felipe Channel, was considered to be an external station. 
Sediments were collected with a van Veen grab of $0.05 \mathrm{~m}^{2}$. Five grab samples were collected; 3 were used for the study of macrofauna $\left(0.15 \mathrm{~m}^{2}\right.$ of total area), the 4th for the granulometry, determined by Buchanan \& Kain's (1984) method, and the 5th sample was used for chemical analyses of the lipid fraction.

Chemical analysis. Fig. 2 shows the protocol used for the isolation and analyses of sediment hydrocarbons. Sediments from each station were well mixed and stored at $-20^{\circ} \mathrm{C}$ in pre-cleaned glass jars and then freeze-dried, homogenized and extracted (approx. $5 \mathrm{~g}$ ) in a $500 \mathrm{ml}$ Soxhlet extractor for $24 \mathrm{~h}$ using a mixture of dichloromethane:methanol $(9: 1, \mathrm{v}: \mathrm{v})$ (modified from Bouloubassi et al. 2001). The elemental sulfur was removed with copper powder (Hostettler \& Kvenvolden 1994). Extracts were reduced in volume on a rotary evaporator and concentrated by gentle nitrogen 'blow down'. The amount of total extractable organic material was determined by gravimetry and expressed as a percentage.
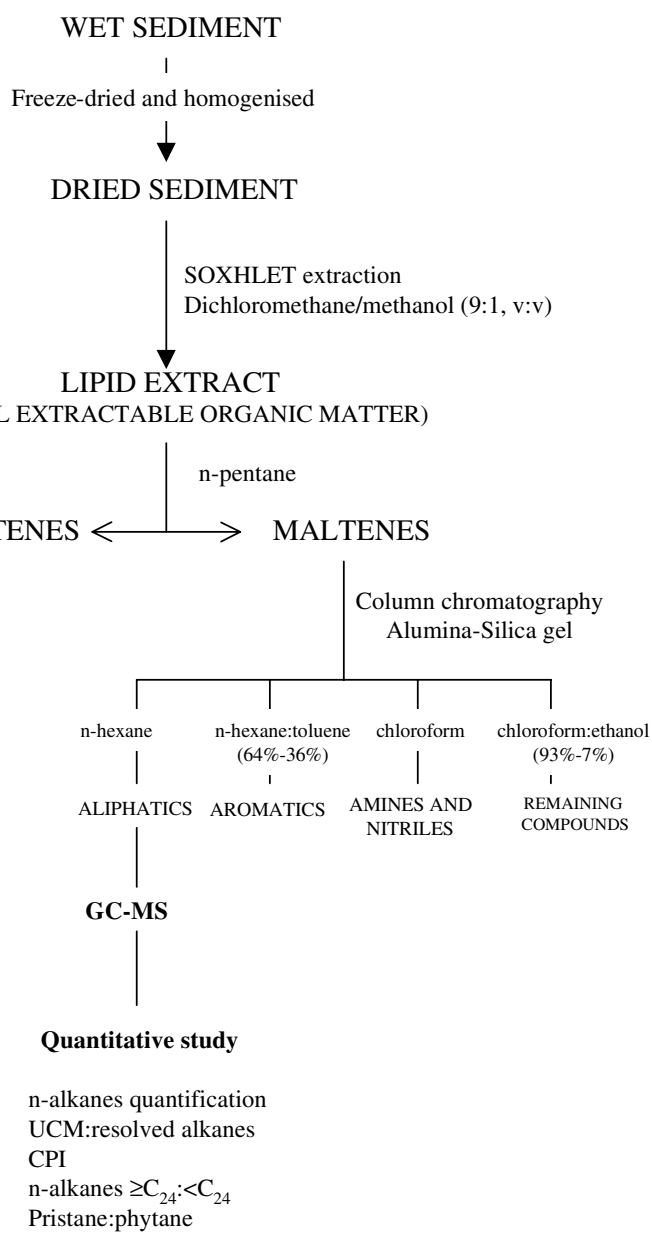

Fig. 2. Chemical protocol for treatment of sediment samples. GC-MS: gas chromatography-mass spectrometry; UCM: unresolved complex mixture; CPI: carbon preference index
Maltene-asphaltene separation and fractionation of maltenes: Total extractable organic materials (the socalled bituminous, or lipid fractions) were mixed with n-pentane to separate the soluble fraction of maltenes from the insoluble one, or asphaltenes. The maltenes were redissolved in dichloromethane and further fractionated on a silica gel:neutral alumina (3:1) column (300 mm length $\times 10 \mathrm{~mm}$ diameter). Aliphatic hydrocarbons were eluted with $35 \mathrm{ml}$ of n-hexane, and the aromatics eluted with $40 \mathrm{ml}$ of n-hexane:toluene (3:1, v:v) (modified from Granda et al. 1993). Toluene was used instead of benzene (see Gogou et al. 2000). The amount of each fraction was determined by gravimetry and the values were expressed in percentages.

Aliphatic hydrocarbons: Aliphatic hydrocarbons were analysed by gas chromatography (GC) and gas chromatography-mass spectrometry (GC-MS). GC analyses were carried out on a Hewlett Packard HP5890 apparatus equipped with a fused silica capillary column (25 $\mathrm{m} \times 0.3 \mathrm{~mm}$ inner diameter), a split-splitness injector (splitness mode was selected), and a flame ionization detector (FID). Helium was used as the carrier gas $\left(1 \mathrm{ml} \mathrm{min}^{-1}\right)$. The oven temperature was held at $50^{\circ} \mathrm{C}$ for $0.8 \mathrm{~min}$, and then increased to $100^{\circ} \mathrm{C}$ at $30^{\circ} \mathrm{C} \mathrm{min}{ }^{-1}$, from $100^{\circ} \mathrm{C}$ to $270^{\circ} \mathrm{C}$ at $6^{\circ} \mathrm{C} \mathrm{min}{ }^{-1}$ and isothermal at $270^{\circ} \mathrm{C}$ for $20 \mathrm{~min}$.

GC-MS analyses were performed in a GCD Hewlett-Packard 5988 system, using the same conditions as for the GC analysis. The electron impact ionization-mode conditions were an ion energy of $70 \mathrm{eV}$. The instrument was operated either in full data acquisition mode or in selected ion monitoring (SIM) mode.

Quantification of the different n-alkane homologues was estimated based on the areas of the chromatographic peaks. The total n-alkane concentration, and some typical indexes giving information on the origin, degree of maturity and redox state of the sediments, such as the carbon preference index (CPI) (Bray \& Evans 1961), the n-alkanes ratio $\geq \mathrm{n}-\mathrm{C}_{24}$ : $<\mathrm{n}-\mathrm{C}_{24}$ (modified from Commendatore et al. 2000) and the pristane:phytane ratio, 2 common isoprenoids, were calculated (Louati et al. 2001). In addition, indicators of oil pollution inputs, such as the area of the unresolved complex mixture (UCM) and the relationship between UCM and resolved alkanes (Readman et al. 2002), were also calculated.

The CPI is used to identify the plant-wax contribution versus fuel contamination, and is calculated by the expression CPI $=2\left(\mathrm{C}_{27}+\mathrm{C}_{29}\right) / \mathrm{C}_{26}+\left(2 \mathrm{C}_{28}\right)+\mathrm{C}_{30}(\mathrm{Com}-$ mendatore et al. 2000). The UCM appears as a hump in the chromatograms and is generally considered to be a mixture of many structurally complex isomers and homologues of branched and cyclic hydrocarbons that 
cannot be resolved by capillary GC columns (Bouloubassi \& Saliot 1993). Using chemical degradation techniques, it has been shown that the UCM consists primarily of linear carbon chains connected at branch points, which result in 'T-shaped' molecules that are resistant to biodegradation, and thus accumulate in sediments (Readman et al. 2002). In general, the presence of a UCM in aliphatic hydrocarbon chromatograms is considered to be associated with degraded or weathered petroleum residues (Readman et al. 2002).

Biological sample processing. The macrofaunal samples were processed through a sieve with a mesh size of $0.5 \mathrm{~mm}$, and the retained fraction was fixed in $4 \%$ neutral formalin stained with Rose Bengal. Organisms were sorted, identified to species level, and counted.

Statistical analyses. The possible differences between the hydrocarbon parameters measured (total extract, total hydrocarbons, the maltenes:asphaltenes, aliphatics:aromatics, and hydrocarbons: to other maltenes ratios, CPI, $\geq \mathrm{n}-\mathrm{C}_{24}:<\mathrm{n}-\mathrm{C}_{24}$ ratio, UCM:resolved alkanes and pristane:phytane ratios) and the macrofaunal abundances between the internal and external stations were explored. The data were tested for normality using the Kolmogorov-Smirnov test and Levene's test for homogeneity of variances, and then analysed for significance using 1-way ANOVAs. When there was not normality and/or homogeneity of variances, the Kruskal-Wallis test was used. The affinities among stations were established through cluster analysis using the UPGMA method (unweighted pair group method using arithmetic averages) (Sneath \& Sokal 1973), based on the Bray-Curtis similarity index for the species matrix and on the euclidean distance for the hydrocarbon matrix. Abundance data of the macrofaunal species were subjected to a double squared-root transformation so that classification and ordination were not determined only by the most dominant species (Clarke \& Green 1988). Hydrocarbon data were transformed with $\log (x+1)$ (Estacio et al. 1997). MDS (non-metric multidimensional scaling) analysis was used on the species matrix, and the Kruskal stress coefficient was used to test the ordination (Kruskal \& Wish 1978, Carballo et al. 1996, Naranjo et al. 1996). Using the hydrocarbon matrix, PCA (principal component analysis) was performed. To explore the relationships among hydrocarbon levels (especially aliphatic indexes) and fauna, canonical correspondence analysis (CCA) was applied. The Monte Carlo test was used to verify the statistical significance of the analysis. Multivariate analyses were carried out using the PRIMER (Plymouth Routines in Multivariate Ecological Research) package (Clarke \& Gorley 2001), and for univariate analyses the BMDP (BioMedical Data Programs) was used (Dixon 1983).

\section{RESULTS}

\section{Lipid characterisation of the sampling stations}

Total extractable organic material ranged between 0.32 and $4.25 \%$ (Table 1). The lowest values were registered at the most sandy stations (both internal and external), while the highest values were measured at the stations of the enclosed fishing harbour (Stns 6 and 7), which were enriched in silt and clay. The differences in total extracts between the internal and external stations were not significant (Table 2). However, the total hydrocarbon concentrations, and specially the maltenes:asphaltenes and hydrocarbons: other maltenes ratios were significantly different outside and inside the harbour (Table 2). The percentage of asphaltenes in the lipid extract of the external stations was lower than the percentages in the internal stations, even after comparison with the most sandy internal stations, which have the lowest contents of silt and clay. Although the most sandy internal stations have similar total organic extract values to the external ones, the percentage of asphaltenes is highest in the internal stations, regardless of granulometry. In most of the internal stations, the asphaltenes accounted for a major part of the total extractable fraction (ranging from 25 to $76 \%$ ), while in the external stations this varied from 4 to $24 \%$ (Table 1).

\section{Aliphatic hydrocarbons}

Gas chromatograms of aliphatic hydrocarbons from the different sites (Fig. 3) showed that sedimentary aliphatic hydrocarbons consisted of a series of resolved compounds, mainly n-alkanes from n- $\mathrm{C}_{12}$ to $\mathrm{n}-\mathrm{C}_{33}$, and a UCM. Total aliphatic hydrocarbon concentrations varied from 400 to $6021 \mathrm{ppm}$. In all of the samples, the aliphatic fraction of the hydrocarbons was higher than the aromatic fraction (Table 1). Both the external and internal stations, with less proportions of silt and clay, showed a similar proportion of resolved hydrocarbons and UCM, with a dominance of short-chain n-alkanes $\left(n-C_{15}\right.$ to $\mathrm{n}-\mathrm{C}_{20}$ ). The internal stations of the most enclosed areas showed a major proportion of long-chain n-alkanes ( $\mathrm{n}-\mathrm{C}_{22}$ to $\mathrm{n}-\mathrm{C}_{28}$ ) and abundant UCM (Fig. 3). The highest value of the UCM:resolved alkanes ratio was obtained at Stn 7 (27.57). While the CPI was not significantly different between internal and external stations, the $\geq n-C_{24}$ : $<\mathrm{n}-\mathrm{C}_{24}$, UCM:resolved alkanes and pristane:phytane ratios showed significative differences (Table 2).

\section{Macrobenthos and hydrocarbons}

A total of 217 macrofaunal species were identified. The dominant species, with abundance of at least $1 \%$ of the 


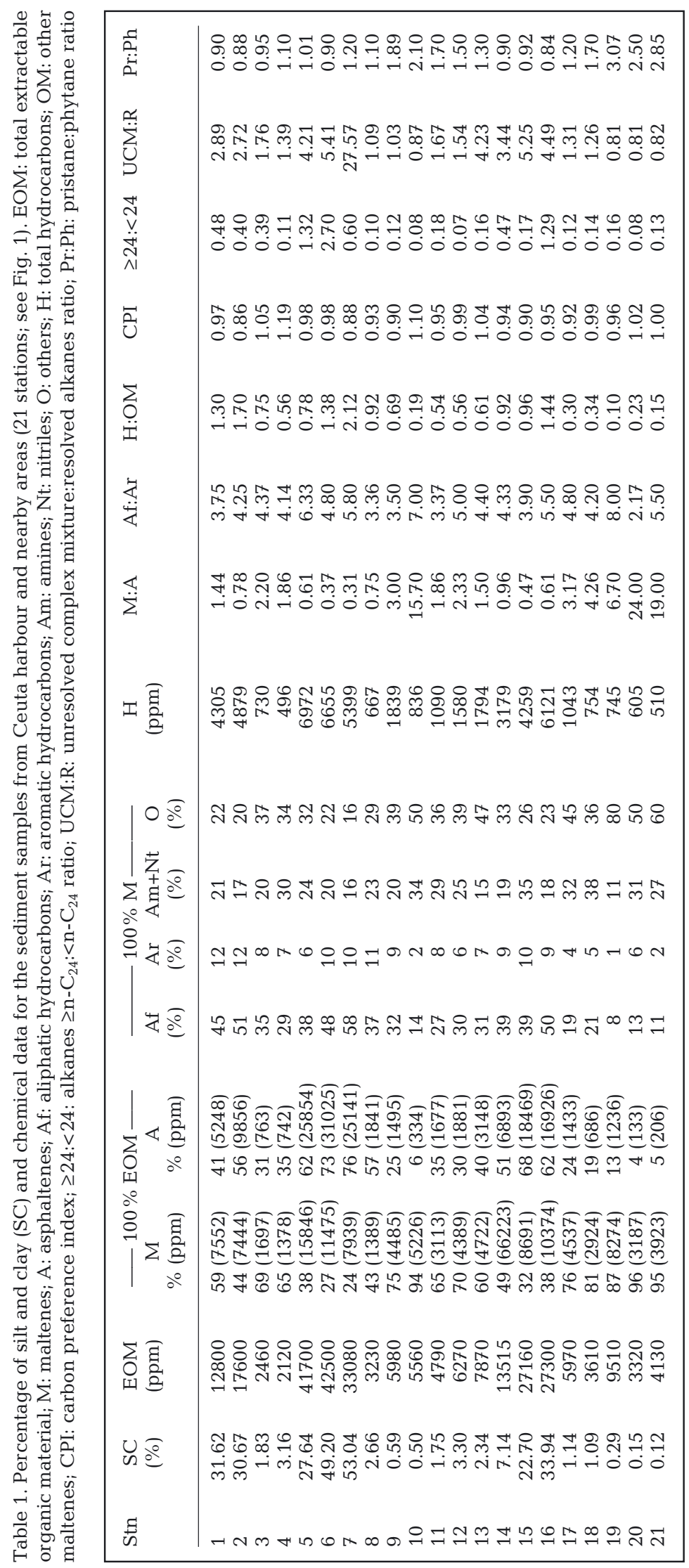

total, are included in Table 3. The crustaceans Corophium runcicorne and C. sextonae, the mollusc Parvicardium exiguum and the polychaete Pseudomalacoceros tridentata were distributed exclusively at internal stations, while the polychaetes Jasmineira elegans and Scoloplos armiger occurred only at external stations. The abundance of the crustaceans Apseudes latreilli, Leptochelia dubia and Pariambus typicus and the polychaetes Capitella capitata, Nereis falsa and Potamilla reniformis, differed significantly between internal and external stations. Abundance differences in macrofaunal species between internal and external stations were confirmed by the 2D representation of the MDS ordination and cluster analysis (Fig. 4). When the hydrocarbon matrix (including the values of total extract, total hydrocarbons, maltenes:asphaltenes, aliphatics:aromatics, and hydrocarbons:other maltenes ratios, $\mathrm{CPI}, \geq \mathrm{n}-\mathrm{C}_{24}:<\mathrm{n}-\mathrm{C}_{24}$, UCM: resolved alkanes and pristane:phytane ratios) was used for the PCA and cluster analysis, a similar ordination of the stations was obtained. Nevertheless, the discrimination between internal and external stations was not evident when the hydrocarbon matrix was used, since the stations are firstly separated into 1 group formed by Stns 1, 2, 5, 6, 7, 14, 15 and 16, and another with the remaining stations. Axis 1 of the PCA showed $77.6 \%$ of the total variance. The Axis 1 scores of the representation were significantly correlated with the percentage of silt and clay in the sediment $(\mathrm{r}=-0.87, \mathrm{p}<$ 0.001) (Fig. 5), and most of the hydrocarbon parameters also correlated with the sediment granulometry (Table 4).

Although some internal stations have similar percentages of silt and clay to external stations (Table 1), the biological data showed differences between the internal and external stations regardless of the granulometry. However, the hydrocarbon parameters seem to be more influenced by granulometry. These parameters discriminated firstly between Stns 1, 2, 3, 6, 7, 14, 15 and 16, those richest in the silt and clay fraction, and the rest of the stations, which have coarser sediments; secondly, the stations with a lower silt/clay fraction were divided into external and internal stations. In spite of the slight differences in the ordination and classification of the stations using these 2 approaches (biotic and chemical data), the relationship between macrofauna and hydrocarbon para- 
Table 2. Chemical parameters measured at internal $(n=15)$ and external $(n=6)$ stations of Ceuta harbour; ns: not significant, ${ }^{*} \mathrm{p}<0.05,{ }^{* *} \mathrm{p}<0.01,{ }^{* * *} \mathrm{p}<0.001$. UCM: unresolved complex mixture

\begin{tabular}{|c|c|c|c|c|c|}
\hline & \multicolumn{2}{|c|}{ Internal stations } & \multicolumn{2}{|c|}{ External stations } & \multirow{2}{*}{$\begin{array}{c}\text { Kruskal-Wallis } \\
K \text {-statistic }\end{array}$} \\
\hline & Mean $\pm \mathrm{SD}$ & Range & Mean $\pm \mathrm{SD}$ & Range & \\
\hline Extractable organic matter (\%) & $1.66 \pm 1.42$ & $0.21-4.25$ & $0.54 \pm 0.23$ & $0.33-0.95$ & $2.67 \mathrm{~ns}$ \\
\hline Hydrocarbons (ppm) & $3331 \pm 2317$ & $496-6972$ & $747 \pm 185$ & $510-1043$ & $5.82^{*}$ \\
\hline Maltenes:asphaltenes ratio & $1.27 \pm 0.83$ & $0.31-3.00$ & $12.14 \pm 8.63$ & $3.17-24.00$ & $12.29^{* * *}$ \\
\hline Aliphatics:aromatics ratio & $4.45 \pm 0.89$ & $3.36-6.33$ & $5.27 \pm 2.07$ & $2.17-8.00$ & $1.19 \mathrm{~ns}$ \\
\hline Hydrocarbons:other maltenes ratio & $1.01 \pm 0.47$ & $0.54-2.12$ & $0.22 \pm 0.09$ & $0.10-0.34$ & $12.29^{* * *}$ \\
\hline Carbon preference index (CPI) & $0.96 \pm 0.08$ & $0.86-1.19$ & $0.99 \pm 0.06$ & $0.92-1.10$ & $1.65 \mathrm{~ns}$ \\
\hline Alkanes $\geq \mathrm{n}-\mathrm{C}_{24}:<\mathrm{n}-\mathrm{C}_{24}$ ratio & $0.57 \pm 0.71$ & $0.07-2.70$ & $0.12 \pm 0.03$ & $0.08-0.16$ & $4.42^{*}$ \\
\hline UCM:resolved alkanes ratio & $4.58 \pm 6.54$ & $1.03-27.57$ & $0.98 \pm 0.24$ & $0.81-1.31$ & $10.19^{* *}$ \\
\hline Pristane:phytane ratio & $1.14 \pm 0.32$ & $0.84-1.89$ & $2.24 \pm 0.71$ & $1.20-3.07$ & $9.26^{* *}$ \\
\hline
\end{tabular}

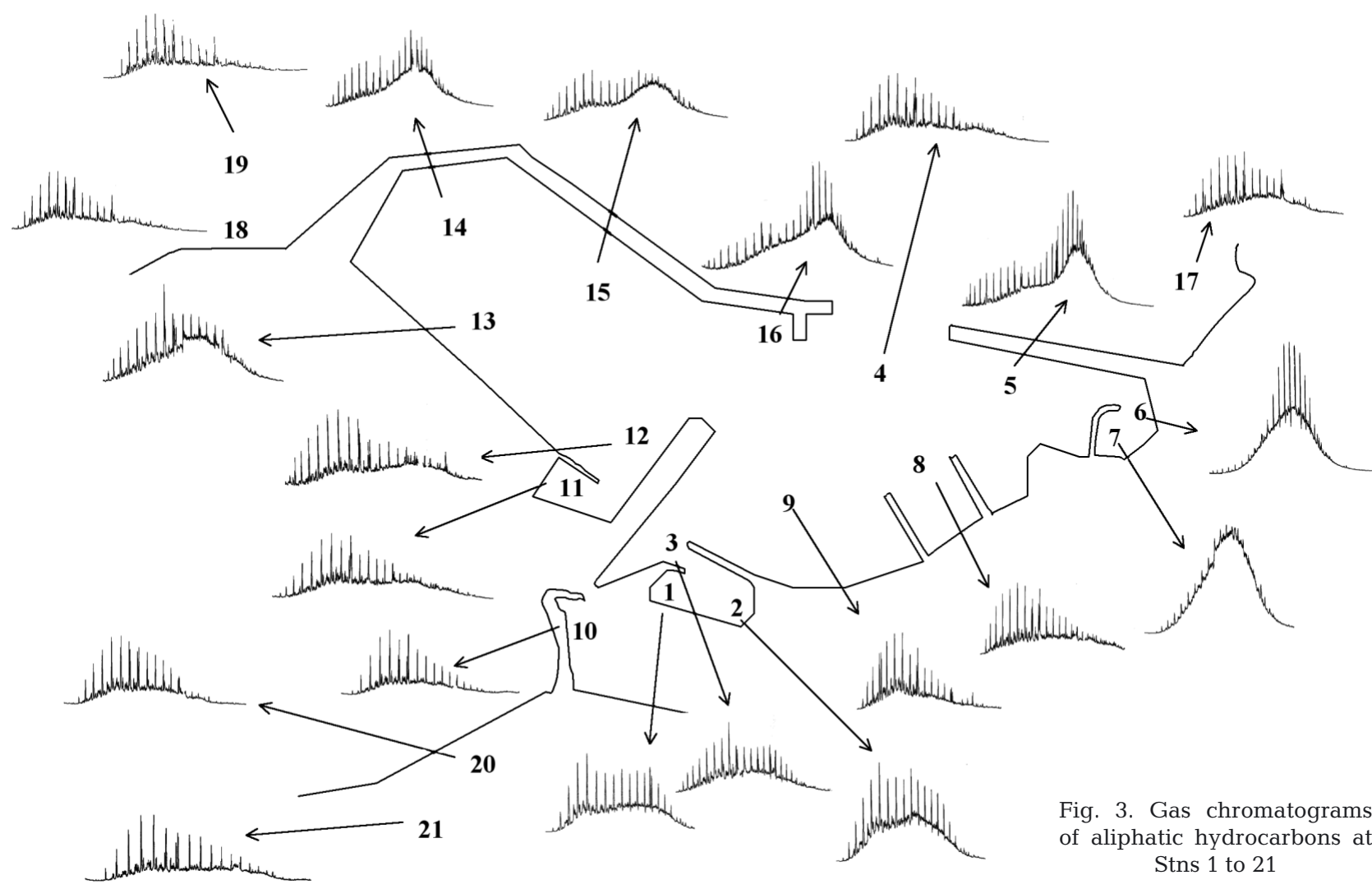

meters is evident in the CCA (Fig. 6, Table 5). Axis 1 separated the external stations with highest values for the maltenes:asphaltenes and pristane:phytane ratios and lowest values of UCM:resolved alkanes and hydrocarbon:other maltenes ratios, from the remaining stations. This axis is strongly correlated with the maltenes:asphaltenes ratio $(\mathrm{r}=-0.943)$. Taking into account the fact that this ratio was not correlated with granulometry, it is one of the most significant ways to explain the ordination 'internal' versus 'external' stations based on species abundances.

\section{DISCUSSION}

\section{Total extractable organic material}

Although the comparison of the total extractable organic material (EOM) with other data reported in the literature is complicated by the variety of extraction methods employed, the values obtained in Ceuta harbour are substantially higher. For instance, in New York Bight, with a high pollution input, a maximum EOM of $0.27 \%$ was reported (Farrington \& Tripp 1977). 
Table 3. Dominant benthic species (abundance $\geq 1 \%$ of total) at Ceuta harbour (ind. per $0.15 \mathrm{~m}^{2} ; \mathrm{mean} \pm \mathrm{SD}$ ); ns: not significant, ${ }^{*} \mathrm{p}<0.05,{ }^{* *} \mathrm{p}<0.01,{ }^{* * *} \mathrm{p}<0.001$

\begin{tabular}{|c|c|c|c|}
\hline & Internal $(\mathrm{n}=15)$ & External $(\mathrm{n}=6)$ & ANOVA $F$-statistic \\
\hline Corophium runcicorne Della Valle 1893 & $13.87 \pm 5.22$ & - & \\
\hline Corophium sextonae Crawford 1937 & $6.40 \pm 2.97$ & - & \\
\hline Parvicardium exiguum (Gmelin 1791) & $13.60 \pm 4.40$ & - & \\
\hline Pseudomalacoceros tridentata (Southern 1914) & $124.93 \pm 24.47$ & - & \\
\hline Jasmineira elegans Joseph 1894 & - & $16.80 \pm 7.81$ & \\
\hline Scoloplos armiger (Müller 1806) & - & $24.20 \pm 2.00$ & \\
\hline Aora spinicornis Afonso 1976 & $8.47 \pm 3.09$ & $8.83 \pm 2.78$ & $0.05 \mathrm{~ns}$ \\
\hline Apseudes latreilli Milne-Edwards 1828 & $168.07 \pm 40.82$ & $15.50 \pm 10.44$ & $5.36^{*}$ \\
\hline Capitella capitata (Fabricius 1780) & $42.87 \pm 18.76$ & $2.33 \pm 2.14$ & $4.88^{*}$ \\
\hline Exogone verugera Claparede 1868 & $7.00 \pm 2.58$ & $3.83 \pm 3.83$ & $0.44 \mathrm{~ns}$ \\
\hline Leptochelia dubia (Kröyer 1842) & $0.27 \pm 0.15$ & $13.17 \pm 8.25$ & $10.18^{* * *}$ \\
\hline Nereis falsa Quatrefages 1865 & $6.20 \pm 1.83$ & $2.16 \pm 1.97$ & $4.81^{*}$ \\
\hline Pariambus typicus Kröyer 1844 & $49.73 \pm 16.26$ & $5.83 \pm 2.55$ & $4.49^{*}$ \\
\hline Potamilla reniformis (Linnaeus 1788) & $8.87 \pm 2.85$ & $0.50 \pm 0.50$ & $9.37^{* *}$ \\
\hline Spisula subtruncata (Da Costa 1778) & $6.20 \pm 2.89$ & $2.67 \pm 2.13$ & $0.30 \mathrm{~ns}$ \\
\hline
\end{tabular}

A

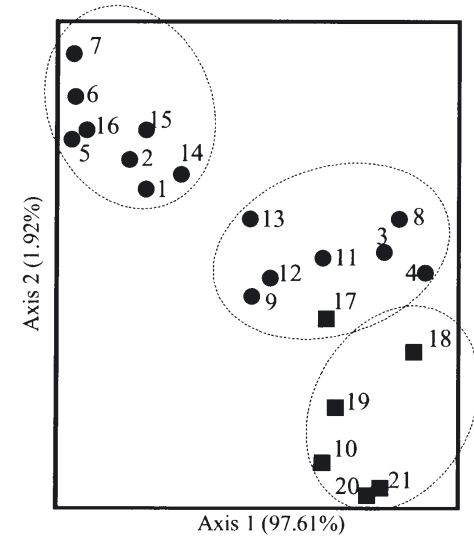

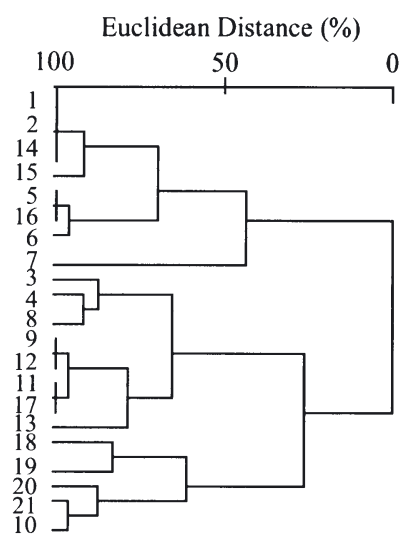

B

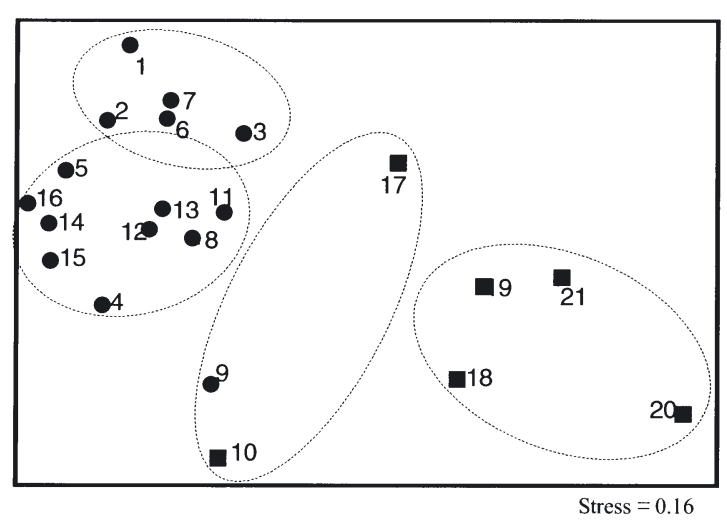

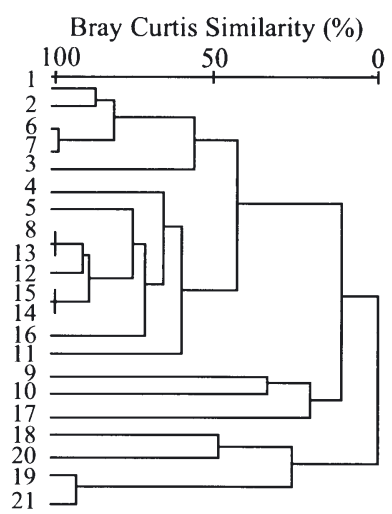

Fig. 4. (A) Principal component analysis (PCA) and cluster analysis of the chemical matrix (extractable organic matter, total hydrocarbons, the maltenes:asphaltenes, aliphatics: aromatics, and hydrocarbons:other maltenes ratios, carbon preference index (CPI), alkanes $\geq \mathrm{n}-\mathrm{C}_{24}:<\mathrm{n}-\mathrm{C}_{24}$, unresolved complex mixture (UCM): resolved alkanes and pristane: phytane ratios). (B) Non-metric multidimensional scaling (MDS) and cluster analysis of species abundance. : internal stations; $\mathbf{0}$ : external stations
When the lipid extract was fractionated into the soluble fraction (maltenes) and the insoluble fraction (asphaltenes), very high percentages of asphaltenes were found, with more than $70 \%$ at Stns 6 and 7 . Asphaltenes have been found to be present in all petroleums in concentrations varying up to as much as
$20 \%$ by weight (Rubinstein et al. 1979). Asphaltenes are heavy molecules (molecular weight $>500$ ) that are difficult to degrade and are characterised by a high heteroatom content and a highly variable chemical composition (Killops \& Killops 1993). Even though asphaltenes can have a major effect on the macro- 
Table 4. Correlation between measured parameters and \% of silt and clay in the sediment. ns: not significant. UCM: unresolved complex mixture

\begin{tabular}{|lrc|}
\hline & $\mathrm{r}$ & $\mathrm{p}$ \\
\hline Hydrocarbons & 0.92 & $<0.001$ \\
Maltenes:asphaltenes ratio & -0.36 & $\mathrm{~ns}$ \\
Aliphatics:aromatic ratio & 0.10 & $\mathrm{~ns}$ \\
Hydrocarbons:other maltenes ratio & 0.88 & $<0.001$ \\
CPI (carbon preference index) & -0.30 & $\mathrm{~ns}$ \\
Alkanes $\geq \mathrm{n}^{-} \mathrm{C}_{24}:<\mathrm{n}^{-} \mathrm{C}_{24}$ ratio & 0.74 & $<0.001$ \\
UCM:resolved alkanes ratio & 0.67 & $<0.001$ \\
Pristane:phytane ratio & -0.54 & $<0.01$ \\
\hline
\end{tabular}

fauna, this is the first study where the maltenes:asphaltenes ratio has been used as a possible contamination index. Furthermore, both the maltenes:asphaltenes and hydrocarbons:other maltenes ratios were able to discriminate significantly between the internal and external stations.

\section{Total hydrocarbons}

The total hydrocarbon concentrations ranged from 496 to $6972 \mathrm{ppm}$. In 'unpolluted' sediments, concentrations generally ranged from $<1 \mathrm{ppm}$ to approximately 10 ppm (Volkman et al. 1992, Bouloubassi \& Saliot 1993), although it may be 2 or 3 times higher where significant inputs of $\mathrm{n}$-alkanes derived from plant waxes occur (Readman et al. 2002). Organic-rich marine sediments may naturally contain up to 100 ppm, but concentrations higher than this are usually associated with petroleum inputs. The maximum values obtained in Ceuta harbour are substantially higher than those from harbours, bays and other sediments worldwide (Table 6). Similar values to those from Ceuta harbour have been reported from extremely polluted environments, such as Saladillo harbour in southern Spain, Narragansett Bay, USA, the Sfax area in Tunisia and the Gulf of Saudi Arabia (Table 6). We might suggest that the high values of total hydrocarbons obtained in Ceuta harbour could be influenced by the quantification method used (gravimetry). Nevertheless, Louati et al. (2001) compared the hydrocarbon concentrations evaluated by gravimetry with the concentrations obtained by FT/IR (fourier transform infrared spectroscopy), and the values were very similar in both methods. The elevated concentrations of total hydrocarbon in Ceuta harbour indicate an important anthropogenic input, in this case derived mainly by loading and

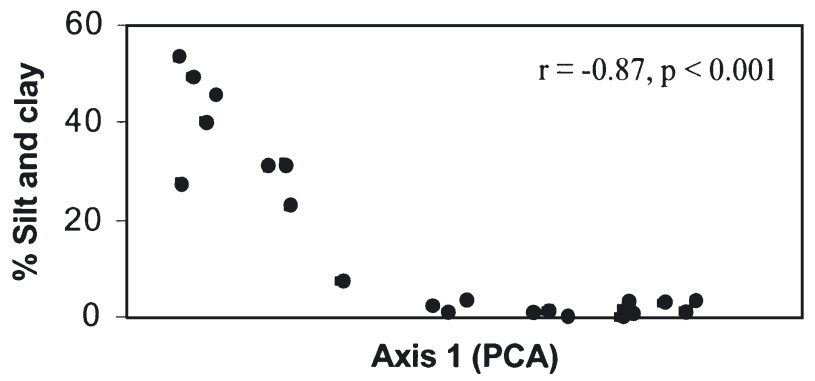

Fig. 5. Scores of principal component analysis (PCA) Axis 1 in relation to percentage of silt and clay in the sediment

dumping in shipping operations, accidental oil spills that have occurred during the last decades, and sewage disposal.

\section{Aliphatic hydrocarbons}

Total aliphatic hydrocarbons varied from 400 to $6021 \mathrm{ppm}$ in the study area. Similar to the total hydrocarbon concentrations, the values of the aliphatic fraction are substantially higher than those from other comparable areas worldwide (Table 6).

\section{Carbon preference index}

High CPI values (>4), together with a dominance of n-alkanes with more than 24 carbons, indicate that the major source of n-alkanes is from terrestrial plants. A CPI close to 1, associated with a predominance of nalkanes with less than 24 carbons, provides evidence that hydrocarbon contamination is from normal petroleum products (Farrington \& Meyers 1975, Hong et al. 1995, Zheng \& Richardson 1999). The values of CPI in Ceuta harbour, ranging from 0.86 to 1.19 , reflect anthropogenic contamination.

Table 5. Summary results of the canonical correspondence analysis (CCA) (see Fig. 6). Only the parameters significantly correlated with CCA axes at $\mathrm{p}<0.05$ are included. UCM: unresolved complex mixture

\begin{tabular}{|lccc|}
\hline & Axis 1 & Axis 2 & Axis 3 \\
\hline Eigenvalue & 0.583 & 0.306 & 0.278 \\
Percentage of species variance & 12.6 & 19.2 & 25.2 \\
Species-environment correlation & 0.987 & 0.959 & 0.964 \\
Correlation with environmental variables & & & \\
Total hydrocarbons (H) & 0.695 & 0.485 & 0.442 \\
Maltenes:asphaltenes ratio (M:A) & -0.943 & - & - \\
Hydrocarbons:other maltenes ratio (H:O) & 0.809 & - & - \\
Carbon preference index (CPI) & - & -0.803 & - \\
Alkanes $\geq$ n- $\mathrm{C}_{24}:<\mathrm{n}-\mathrm{C}_{24}$ ratio ( $\left.\geq 24:<24\right)$ & 0.440 & 0.400 & - \\
UCM:resolved alkanes ratio (UCM:R) & 0.628 & 0.416 & - \\
Pristane:phytane ratio (Pr:Ph) & -0.821 & - & - \\
\hline
\end{tabular}




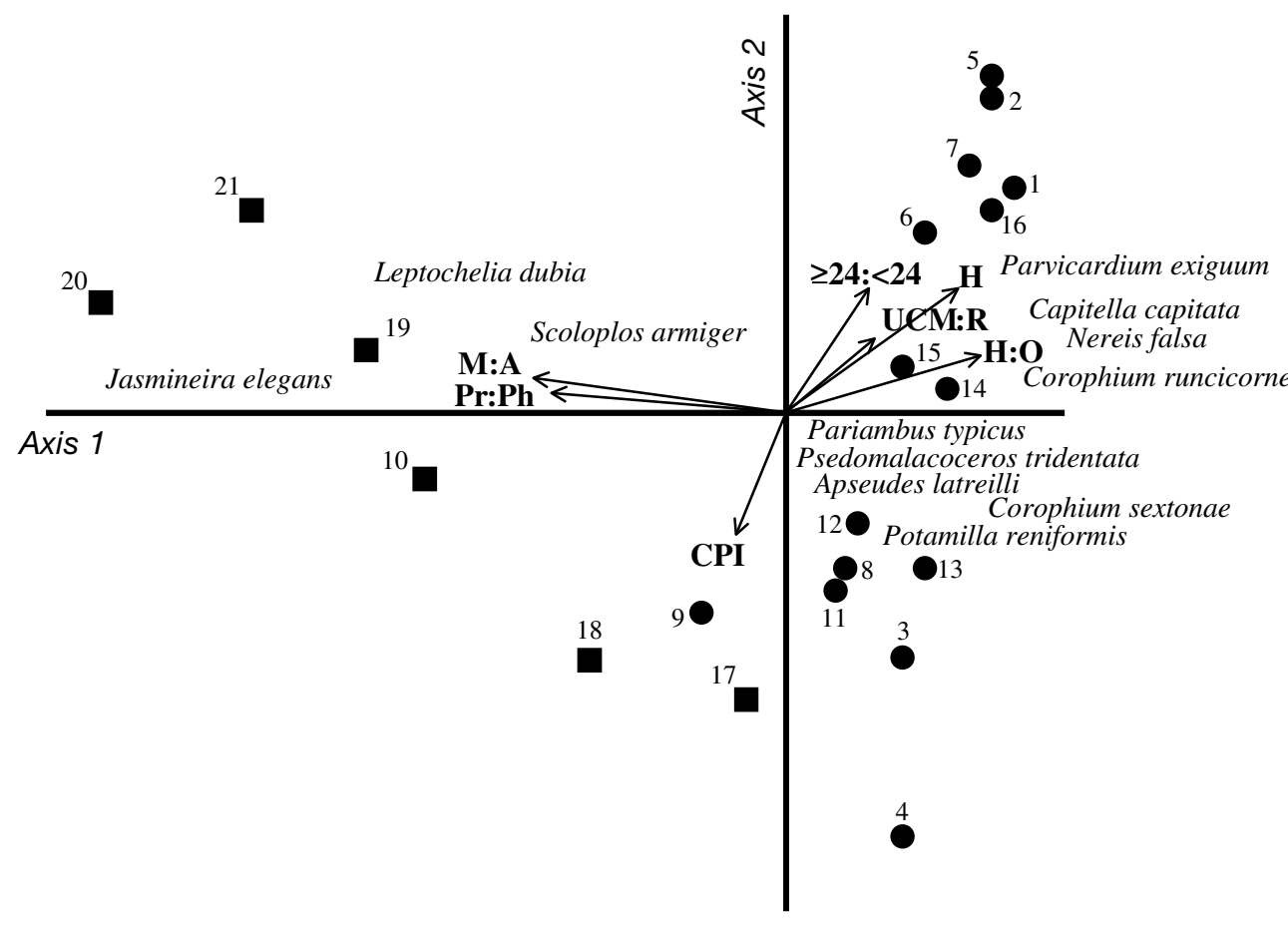

Fig. 6. Canonical correspondence analysis (CCA) of extractable organic matter (EOM), total hydrocarbons $(\mathrm{H})$, maltenes:asphaltenes ratio (M:A), aliphatics: aromatics ratio (Af:Ar), hydrocarbons:other maltenes ratio $(\mathrm{H}: \mathrm{O})$ carbon preference index (CPI), alkanes $\geq$ n- $\mathrm{C}_{24}:<$ n- $\mathrm{C}_{24}$ ratio $(\geq 24$ : $<24$ ), unresolved complex mixture (UCM):resolved alkanes ratio (UCM:R) and pristane:phytane ratio (Pr:Ph), as well as biotic matrix of abundances. EOM and Af:Ar were not included in the graph since these parameters were not significantly correlated with any of the 3 axes. : internal stations; 口: external stations. Vectors pointing away from the origin have a negative component

Table 6. Chemical data for surficial sediments of different regions worldwide reported in the literature. H: total hydrocarbons; A: aliphatic hydrocarbons; UCM:R: unresolved complex mixture:resolved alkanes ratio; CPI: carbon preference index; Pr:Ph: pristane:phytane ratio

\begin{tabular}{|c|c|c|c|c|c|c|}
\hline Location & $\mathrm{H}(\mathrm{ppm})$ & A (ppm) & $\mathrm{UCM}: \mathrm{R}$ & CPI & $\operatorname{Pr}: \mathrm{Ph}$ & Source \\
\hline Antarctica & $<0.5$ & - & - & - & - & Lenihan et al. (1990) \\
\hline Black Sea & $2.0-300.0$ & - & - & - & - & Readman et al. (2002) \\
\hline Cartagena Bay, Colombia & $2.2-1415.4$ & - & - & - & - & Parga-Lozano et al. (2002) \\
\hline Changjiang Estuary, China & - & $2.2-11.8$ & $1.4-11.5$ & $1.1-2.1$ & - & Bouloubassi et al. (2001) \\
\hline Copenhagen Sound, Denmark & $46.0-1800.0$ & - & - & - & - & Jensen (1981) \\
\hline $\begin{array}{l}\text { Cretan Sea, Eastern Medi- } \\
\text { terranean }\end{array}$ & - & $0.6-5.7$ & $1.6-9.6$ & $2.1-4.4$ & - & Gogou et al. (2000) \\
\hline Eastern Harbour, Egypt & - & $61.0-1357.0$ & - & - & - & Tarek et al. (1995) \\
\hline Great Barrier Reef & $0.5-2.0$ & - & - & - & - & Volkman et al. (1992) \\
\hline Great Britain coast & $40.0-3000.0$ & - & - & - & - & Whittle et al. (1982) \\
\hline Gulf of Kuwait & $40.0-240.0$ & - & - & - & - & Readman et al. (1996) \\
\hline Gulf of Mexico & - & $42.0-232.0$ & - & - & - & Gearing et al. (1976) \\
\hline Gulf of Saudi Arabia & $11.0-6900.0$ & - & - & - & - & Readman et al. (1996) \\
\hline Ceuta harbour, North Africa & $496.0-6972.2$ & $399.6-6021.5$ & $0.8-27.6$ & $0.9-1.2$ & $0.9-3.1$ & Present study \\
\hline Hong Kong, China & $4.5-1996.0$ & - & $2.5-28.9$ & - & - & Zheng \& Richardson (1999) \\
\hline Narragansett Bay, USA & $500.0-5700.0$ & - & - & - & - & Farrington \& Quinn (1973) \\
\hline New York Bight, USA & - & $2.0-1200.0$ & - & - & - & Farington \& Tripp (1977) \\
\hline Patagonia, Argentina & - & $0.0-1304.7$ & $4.3-51.3$ & $0.5-4.7$ & $0.3-1.7$ & Commendatore et al. (2000) \\
\hline Puget Sound, Thailand & - & $4.0-350.0$ & - & - & - & Barrick et al. (1980) \\
\hline $\begin{array}{l}\text { Saladillo Harbour, } \\
\text { southern Spain }\end{array}$ & $13.0-4415.0$ & - & - & - & - & Estacio et al. (1997) \\
\hline São Sebastião, Brazil & - & $0.2-4.1$ & - & $1.2-3.2$ & $0.7-2.8$ & Zanardi et al. (1999) \\
\hline Scotian Shelf, Canada & - & $8.0-20.2$ & $0.9-25.0$ & $1.1-5.3$ & $1.0-10.2$ & Keizer et al. (1978) \\
\hline Sfax area, Tunisia & $1121.0-5217.0$ & $303.0-2268.0$ & $1.0-13.7$ & $0.8-1.5$ & $0.2-0.6$ & Louati et al. (2001) \\
\hline $\begin{array}{l}\text { Turkey, Russia and Ukrania } \\
\text { (Black Sea) }\end{array}$ & $2.1-310.0$ & $1.2-240.0$ & $1.3-28.6$ & - & $0.1->45$ & Readman et al. (2002) \\
\hline Victoria Harbour, China & - & $60.0-646.0$ & - & - & - & Hong et al. (1995) \\
\hline Xiamen Harbour, China & - & $3.1-3.3$ & - & - & - & Hong et al. (1995) \\
\hline Yellow Sea & - & $1.9-64.8$ & $0.0-4.2$ & $1.3-2.9$ & $0.5-1.5$ & Wu et al. (2001) \\
\hline
\end{tabular}


Unresolved complex mixture

In general, the presence of a UCM in aliphatic hydrocarbon chromatograms is considered to be associated with degraded or weathered petroleum residues (Farrington \& Tripp 1977, Le Dreau et al. 1997, Readman et al. 2002). Smaller contributions, in the low ppm dry weight range can, however, relate to bacterial reworking of sedimentary organic matter from the weathering of ancient rocks (Volkman et al. 1992, Readman et al. 2002). The relative importance of the UCM, expressed as the ratio of unresolved to resolved compounds, is used as diagnostic criteria of pollutant inputs (Bouloubassi et al. 2001, Readman et al. 2002). Significant contamination by petroleum products exists when the value is $\geq 2$ according to Simoneit (1986) and $>4$ according to Mazurek \& Simoneit (1984) and Lipiatou \& Saliot (1991). Some of the internal stations, especially those located in the most enclosed areas, such as Stns 1, 2, 6, 7 and 16, presented a clear dominance of the unresolved compounds indicating high petroleum contributions to these sediments. The high values of the UCM in sediment samples, as with those obtained in the present study, have been reported as evidence of chronic oil-pollution (Gogou et al. 2000).

\section{Isoprenoid hydrocarbons}

Another useful indicator of the hydrocarbon origin is the ratio of the isoprenoids pristane and phytane. Pristane $(2,6,10,14$-tetramethylpentadecane) is usually found in zooplankton and other marine animals, while phytane $(2,6,10,14$-tetramethylhexadecane) is reported as a normal component of oil (Gilbert et al. 1992, Noboru-Nishigima et al. 2001). In uncontaminated sediments, the pristine:phytane ratio is higher than 1, and between 3 and 5 (Steinhauer \& Boehm 1992). At Ceuta harbour, the pristane:phytane ( $\mathrm{Pr}: \mathrm{Ph})$ ratio is close to 1 in most of the internal stations. These levels suggest oil contamination (Steinhauer \& Boehm 1992).

\section{Relationships between hydrocarbons and macrofauna}

The multivariate approach showed a significant correspondence between macrofaunal composition and hydrocarbon parameters, discriminating between the internal and external stations at Ceuta harbour. This is the first time in which traditional indicators of petroleum pollution as the UCM:resolved alkanes, $\mathrm{Pr}: \mathrm{Ph}$ ratios and CPI are assayed in a biotic ordination. The maltenes:asphaltenes ratio, which had never been included in previous studies, is, in fact, the main discriminating factor between the internal and external sta- tions relating to species composition. Most of the chemical measures separated the stations firstly by granulometry, regardless of the internal/external location. Due to the particular configuration of Ceuta harbour, which includes a channel that increases water renewal, there are stations inside the harbour with similar sediment characteristics to the external stations and both are grouped together in the classification and ordination analyses. This provides a useful tool to test the indexes. However, the macrobenthic communities separated the internal from the external stations, regardless of granulometry. Therefore, it was expected that some factors correlating more with location of the stations (internal/external) than with granulometry should affect the differences in the macrofauna. The results of this study conclude that the maltenes:asphaltenes ratio is one of the main factors affecting macrofauna distribution. The polychaetes Jasmineira elegans and Scoloplos armiger were the most sensitive species to increases in the asphaltene percentage in the sediments inside the harbour. In fact, these species were exclusively found at external stations, and were absent from inside the harbour. These worms were not even found at the internal stations with higher sand content (e.g. Stns 3, 4, 8, 9, 12), which have similar grain size to the external stations. The tanaid Leptochelia dubia also showed preference for the external stations and were almost absent inside the harbour. The species which were distributed exclusively at the internal stations were dominant in the sedimentary accreting areas found to be rich in silt and clay contents; however, they were also present at those internal stations that had a high sand content. Although granulometry could affect the differences in the abundance of these species across the inner stations, their presence at the sandy inner stations and absence at the sandy outer stations support the hypothesis that there are additional factors other than granulometry that affect macrobenthic assemblages. For example, the bivalve Parvicardium exiguum, which is considered to inhabit sediment rich in silt, clay and organic matter (Lastra et al. 1993), and the polychaete Pseudomalacoceros tridentata have been found at the inner sandy stations but not outside the harbour. The dominance of the opportunistic polychaete Capitella capitata inside the harbour is traditionally considered to be indicative of environmental perturbations. Although it is known that sediment characteristics are important regulatory factors of macrobenthic assemblages (Gray 1981, Estacio et al. 1997), this study shows that, under stressful environmental conditions, further factors such as the maltenes:asphaltenes ratio are involved in the ordination of species, independent of sediment grain size. As mentioned above, asphaltenes do not degrade easily, and have accumulated in Ceuta harbour sedi- 
ments. Oudot et al. (1998) conducted an experimental study focused on the weathering rates of crude oil using sediments from a French estuary. They estimated biodegradation rates for total oil $(40 \%)$, aliphatics $(83 \%)$ and aromatics $(55 \%)$, and pointed out that asphaltenes had not been degraded. Likely, the negative effect of high concentrations of asphaltenes in the macrofauna could be related to a physical, rather than chemical, effect, since these compounds are considerably thick and viscous. Further experimental studies on the faunal responses to different proportions of asphaltenes under controlled conditions are needed. The maltenes:asphaltenes ratio, and secondly the hydrocarbon:other maltenes ratio, should be used in future studies related to hydrocarbon pollution assessment, and the implications to the macrofauna composition. An integrated treatment including both chemical and biological approaches could be useful to evaluate the anthropogenic level of hydrocarbon pollution and the main parameters affecting macrofaunal assemblages.

Acknowledgements. We express our thanks to Compañía del Mar and Club Calypso for assistance in the field, and Julio and Rosa for helping with the chemical analysis. Thanks are also due to Dr. A. Baldinger for the English revision of the manuscript. Our gratitude to Asamblea de Ceuta and a grant 'Programa de Formación de Profesorado Universitario AP98/28617065' from the Ministry of Education, Culture and Sport of Spain for financial support. We are very grateful to 4 anonymous reviewers for their valuable comments and suggestions, which substantially improved the manuscript.

\section{LITERATURE CITED}

Al-Omran LA, Rao CVN (1999) The distribution and sources of hydrocarbons in the regional sea area of the Arabian Gulf. Kuwait J Sci Eng 26:301-314

Barrick RC, Hedges JI, Paterson ML (1980) Hydrocarbon geochemistry of the Puget Sound region. Sedimentary acyclic hydrocarbons. Geochim Cosmochim Acta 44:1349-1362

Bouloubassi I, Saliot A (1993) Investigation of anthropogenic and natural organic inputs in estuarine sediments using hydrocarbon markers (NAH, LAB, PAH). Oceanol Acta 16: 145-161

Bouloubassi I, Lipiatou E, Saliot A, Tolosa I, Bayona JM, Albaiges J (1997) Carbon sources and cycle in the Western Mediterranean: II. The use of molecular markers to determine the origin of organic matter. Deep-Sea Res 44: 781-799

Bouloubassi I, Fillaux J, Saliot A (2001) Hydrocarbons in surface sediments from the Changjiang (Yangtze River) Estuary, East China Sea. Mar Pollut Bull 42:1335-1346

Bray EE, Evans ED (1961) Distribution of n-paraffins as a clue to recognition of source beds. Geochim Cosmochim Acta 22:2-15

Buchanan JB, Kain JM (1984) Measurement of the physical and chemical environment. In: Holme NA, McIntyre AD (eds) Methods for the study of marine benthos. Blackwell Scientific Publications, Oxford, p 30-50

Carballo JL, Naranjo SA, García-Gómez JC (1996) Use of marine sponges as stress indicators in marine ecosystems at Algeciras Bay (southern Iberian Peninsula). Mar Ecol Prog Ser 135:109-122

Choiseul V, Wilson JG, Nixon E (1998) The distribution of hydrocarbons on the East and South-West Irish Coasts and in the Liffey Estuary. Biol Environ Proc R Ir Acad 98:75-86

Clarke KR, Gorley RN (2001) PRIMER (Plymouth Routines In Multivariate Ecological Research) v5: user manual/ tutorial. PRIMER-E, Plymouth

Clarke KR, Green RH (1988) Statistical design and analysis for a 'biological effects' study. Mar Ecol Prog Ser 46: $213-226$

Commendatore MG, Esteves JL, Colombos JC (2000) Hydrocarbons in coastal sediments of Patagonia, Argentina: levels and probable sources. Mar Pollut Bull 40:989-998

Dachs J, Bayona JM, Fillaux J, Saliot A, Albaigés J (1999) Evaluation of anthropogenic and biogenic inputs into the western Mediterranean using molecular markers. Mar Chem 65:195-210

Dauer DM, Luckenbach MW, Rodi AJ (1993) Abundance biomass comparison ( $\mathrm{ABC}$ method) effects of an estuarine gradient, anoxic/hypoxic events and contaminated sedimens. Mar Biol 116:507-518

Dixon WJ (1983) BMDP statistical sofware. University California Press, Berkeley

Estacio FJ, García-Adiego EM, Fa DA, García-Gomez JC, Daza JL, Hortas F, Gómez-Ariza JL (1997) Ecological analysis in a polluted area of Algeciras Bay (Southern Spain): external 'versus' internal outfalls and environmental implications. Mar Pollut Bull 34:780-793

Farrington JW, Meyers PA (1975) Hydrocarbons in the marine environment. In: Eglington G (ed) Environmental chemistry, specialists periodical report. The Chemical Society, London, p 109-136

Farrington JW, Quinn JG (1973) Petroleum hydrocarbons in Narragansett Bay. I. Survey of hydrocarbons in sediments and clams (Mercenaria mercenaria). Estuar Coast Mar Sci $1: 71-79$

Farrington JW, Tripp BW (1977) Hydrocarbons in western North Atlantic surface sediments. Geochim Cosmochim Acta 41:1627-1641

Gearing P, Gearing JN, Lytle TF, Lytle JS (1976) Hydrocarbons in 60 northeast Gulf of Mexico shelf sediments: a preliminary survey. Geochim Cosmochim Acta 40: 1005-1017

Gilbert M, Rivet L, Jawad AI, Bertrand JC (1992) Hydrocarbon distributions in low polluted surface sediments from Kuwait, Bahrain and Oman Coastal Zones (before the Gulf War). Mar Pollut Bull 24:622-626

Gogou A, Bouloubassi I, Stephanou EG (2000) Marine organic geochemistry of the Eastern Mediterranean: I. Aliphatic and polyaromatic hydrocarbons in Cretan Sea surficial sediments. Mar Chem 68:265-282

Granda M, Menéndez R, Bernard P, Bermejo J (1993) Efficiency of extrography in the fractionation of coal-derived oils. Fuel 72:397-403

Gray JS (1981) The ecology of marine sediments. An introduction to the structure and function of benthic communities. Cambridge University Press, Cambridge

Hong HS, Xu L, Zhang L, Chen JC, Wong YS, Wan TSM (1995) Environmental fate and chemistry of organic pollutants in the sediment of Xiamen and Victoria Harbours. Mar Pollut Bull 31:229-236

Hostettler FD, Kvenvolden KA (1994) Geochemical changes in crude oil spilled from the Exxon Valdez supertanker into Prince William Sound, Alaska. Org Geochem 21: 927-936

Jensen K (1981) Levels of hydrocarbons in mussels, Mytilus 
edulis, and surface sediments from Danish coastal areas. Bull Environ Contam Toxicol 26:202-206

Keizer PD, Dale J, Gordon DC (1978) Hydrocarbons in surficial sediments from the Scotian Shelf. Geochim Cosmochim Acta 42:165-172

Killops SD, Killops VJ (1993) An introduction to organic geochemistry. John Wiley \& Sons, New York

Kruskal JB, Wish M (1978) Multidimensional scaling. Sage Publications, Beverly Hills, CA

Lastra M, Sánzhez A, Mora J (1993) Population dynamics and secondary production of Parvicardium exiguum (Gmelin, 1790 ) in Santander Bay (N of Spain). J Molluscan Stud 59: $73-81$

Le Dreau Y, Jacquot F, Doumenq P, Guiliano M, Bertand JC, Mille G (1997) Hydrocarbon balance of a site which had been highly and chronically contaminated by petroleum wastes of a refinery (from 1956 to 1992). Mar Pollut Bull 34:456-468

Lenihan HS, Oliver JS, Oakden JM, Stephenson MD (1990) Intense and localized benthic marine pollution around McMurdo station, Antarctica. Mar Pollut Bull 21:422-430

Lipiatou E, Saliot A (1991) Hydrocarbon contamination of the Rhône delta and western Mediterranean. Mar Pollut Bull 22:297-304

Louati A, Elleuch B, Kallel M, Saliot A, Dagaut J, Oudot J (2001) Hydrocarbon contamination of coastal sediments from the Sfax area (Tunisia), Mediterranean Sea. Mar Pollut Bull 42:445-452

Mazurek MA, Simoneit BRT (1984) Characterization of biogenic and petroleum-derived organic matter in aerosols over remote, rural and urban areas. In: Keith LH (ed) Identification and analysis of organic pollutants in air. Ann Arbor Science, Butterworth Publishers, Boston, p 353-378

Naranjo SA, Carballo JL, García-Gómez JC (1996) Effects of environmental stress on ascidian populations in Algeciras Bay (southern Spain). Possible marine bioindicators? Mar Ecol Prog Ser 144:119-131

Noboru-Nishigima F, Roland-Weber R, Caruso-Bícego M (2001) Aliphatic and aromatic hydrocarbons in sediments of Santos and Cananéia, SP, Brazil. Mar Pollut Bull 42: 1064-1072

Oudot J, Merlin FX, Pinvidic P (1998) Weathering rates of oil components in a bioremediation experiment in estuarine sediments. Mar Environ Res 45:113-125

Oug E, Naes K, Rygg B (1998) Relationship between soft bottom macrofauna and polycyclic aromatic hydrocarbons (PAH) from smelter discharge in Norwegian fjords and coastal waters. Mar Ecol Prog Ser 173:39-42

Parga-Lozano $\mathrm{CH}$, Marrugo-Gónzalez AJ, FernándezMaestre R (2002) Hydrocarbon contamination in Cartagena Bay, Colombia. Mar Pollut Bull 44:71-81

Pereira We, Hostettler FD, Luoma SN, van Geen A, Fuller CC, Anima RJ (1999) Sedimentary record of anthropogenic and biogenic polycyclic aromatic hydrocarbons in San Francisco Bay, California. Mar Chem 64:99-113

Preston BL (2002) Spatial patterns in benthic biodiversity of Chesapeake Bay, USA (1984-1999): association with water quality and sediment toxicity. Environ Toxicol Chem 21:151-162

Rakocinski CF, Brown SS, Gaston GR, Heard RW, Walker WW,

Editorial responsibility: Otto Kinne (Editor),

Oldendorf/Luhe, Germany
Summers JK (2000) Species-abundance-biomass responses by estuarine macrobenthos to sediment chemical contamination. J Aquat Ecosyst Stress Recovery 7:201-214

Readman JW, Bartocci J, Tolosa I, Fowler SW, Oregioni B, Abdulraheem MY (1996) Recovery of the coastal marine environment in the Gulf following the 1991 war related oil spills. Mar Pollut Bull 32:493-498

Readman JW, Fillmann G, Tolosa I, Bartocci J, Villeneuve JP, Catinni C, Mee LD (2002) Petroleum and PAH contamination of the Black Sea. Mar Pollut Bull 44:48-62

Rubinstein I, Spyckerelle C, Strausz OP (1979) Pyrolysis of asphaltenes: a source of geochemical information. Geochim Cosmochim Acta 43:1-6

Saíz-Salinas JI (1997) Evaluation of adverse biological effects induced by pollution in the Bilbao Estuary (Spain). Environ Pollut 96:351-359

Sharma VK, Hicks SD, Rivera W, Vazquez FG (2002) Characterization and degradation of petroleum hydrocarbon following an oil spill into a coastal environment of south Texas, USA. Water Air Soil Pollut 134:111-127

Simoneit BRT (1986) Characterization of organic constituents in aerosols in relation to their origin and transport: a review. Int J Environ Anal Chem 23:207-237

Sneath PHA, Sokal RR (1973) Numerical taxonomy. The principles and practique of numerical classification. WWH Freeman, San Francisco

Steinhauer MS, Boehm PD (1992) The composition and distribution of saturated and aromatic hydrocarbons in nearshore sediment, river sediments, and coastal peat of the Alaskan Beaufort Sea: implications for detecting anthropogenic hydrocarbon inputs. Mar Environ Res 33:223-253

Tarek AT, Aboul-Kassim, Simoneit BRT (1995) Petroleum hydrocarbons fingerprinting and sediment transport assessed by molecular biomarker and multivariat statistica analyses in the eastern harbour of Alexandria, Egypt. Mar Pollut Bull 30:63-73

Vandermeulen JH, Gordon DC (1976) Reentry of five year old stranded Bunker $\mathrm{C}$ fuel oil from a low energy beach into the water, sediments and biota of Chedabucto Bay, Nova Scotia. J Fish Res Board Can 33:2002-2010

Volkman JK, Holdsworth DG, Neil GP, Bavor HJ Jr (1992) Identification of natural, anthropogenic and petroleum hydrocarbons in aquatic sediments. Sci Total Environ 112: 203-219

Whittle KJ, Hardy R, Mackie PR, McGill AS (1982) A quantitative assessment of the sources and fate of petroleum compounds in the marine environment. In: Clark RB (ed) The long-term effects of oil pollution on marine populations, communities and ecosystems. Phil Trans R Soc Lond 297:193-218

Wu Y, Zhang J, Mi T, Li B (2001) Occurrence of n-alkanes and polycyclic aromatic hydrocarbons in the core sediments of the Yellow Sea. Mar Chem 76:1-15

Zanardi E, Bicego MC, De Miranda LB, Weber RR (1999) Distribution and origin of hydrocarbons in water and sediments in São Sebastião, SP, Brazil. Mar Pollut Bull 38: 261-267

Zheng GJ, Richardson BJ (1999) Petroleum hydrocarbons and polycyclic aromatic hydrocarbons (PAHs) in Hong Kong marine sediments. Chemosphere 38:2625-2632

Submitted: November 26, 2002; Accepted: September 7, 2003 Proofs received from author(s): November 19, 2003 